\title{
Paving the Way towards Highly Stable and Practical Electrolytes for Rechargeable Magnesium Batteries
}

\author{
Oscar Tutusaus ${ }^{[a, b]}$ and Rana Mohtadi ${ }^{[a]}$
}

\begin{abstract}
Despite being considered a promising anode candidate for future battery technologies, the reactivity of $\mathrm{Mg}$ metal and its resultant passivation have challenged the development of electrolytes for rechargeable Mg batteries. In this Concept article, we shed light on critical past and current motivations, hurdles, and design strategies of electrolyte development for $\mathrm{Mg}$ batteries. Special focus is given to the most recent advancements; in particular, we elaborate on bottom-up design strat-
\end{abstract}

egies targeted to overcome the corrosion issue caused by current electrolyte systems. Salts containing the $\mathrm{B}-\mathrm{H}$ motif expanded the portfolio of $\mathrm{Mg}$-compatible electrolytes and are used as a platform to create a whole new promising family. Here, we explain the approach, challenges, and the path forward for ultimately creating Mg-compatible, highly stable, and non-corrosive $\mathrm{Mg}$ electrolytes.

\section{Introduction}

Over the past two decades, rechargeable batteries have played an instrumental role in driving the evolution of new products and technologies for portable, automotive, and grid-stationary applications. Nowadays, in a state-of-the-art rechargeable Liion battery, $240 \mathrm{Wh} \mathrm{kg}^{-1}$ ( $640 \mathrm{Wh} \mathrm{L}^{-1}$ ) can be provided for thousands of cycles. ${ }^{[1]}$ Yet, there is an increasing gap between the energy demand and the amount of energy that current rechargeable battery technologies can offer.

The energy density of a battery is determined by the anode and cathode materials, specifically by their capacity (total number of electrons stored in the active material) and their voltage difference. Therefore, owing to a high volumetric capacity, that is, $3832 \mathrm{mAh} \mathrm{cm}^{-3}, \mathrm{Mg}$ metal has recently attracted increased attention as a battery anode candidate. ${ }^{[2]}$ Despite the fact that $\mathrm{Mg}$ metal is a priori less competitive than lithium metal, on both specific capacity $\left(2205 \mathrm{mAhg}^{-1}\right.$ vs. $3862 \mathrm{mAh} \mathrm{g}^{-1}$ for lithium) and redox potential levels, the electrochemical processes related to $\mathrm{Mg}$ reversible plating/stripping have, so far, demonstrated the absence of dendrite formation, ${ }^{[3]}$ alleviating the safety concerns associated with lithium-metal anodes. ${ }^{[4]}$ Moreover, the use of Mg may offer an opportunity for battery cost reductions because of its abundance in the earth's crust (it is the fifth most abundant element). ${ }^{[2,3 a]}$

Despite the traits of $\mathrm{Mg}$ metal, the development of rechargeable $\mathrm{Mg}$ batteries has been faced with several technical

[a] Dr. O. Tutusaus, Dr. R. Mohtadi

Materials Research Department

Toyota Research Institute of North America

1555 Woodridge Ave, Ann Arbor, MI 48105 (USA)

E-mail: rana.mohtadi@tema.toyota.com

[b] Dr. O. Tutusaus

Department of Chemistry, University of Michigan

930 North University Avenue, Ann Arbor, MI 48109 (USA)

Supporting Information for this article is available on the WWW under http://dx.doi.org/10.1002/celc.201402207. challenges. These are manifested by the absence of practical high capacity, high-voltage cathodes, and appropriate electrolytes. ${ }^{[2]}$ As electrolytes are the medium that link the anode to the cathode, they should, at the very minimum, possess a sufficient electrochemical stability window against electroreduction and electrooxidation together with acceptable electrochemical transport. To become practical, other physical and chemical properties are also desirable (Figure 1). Indeed, the ultimate need to simultaneously satisfy a myriad of requirements makes the development of electrolytes a challenging endeavour.

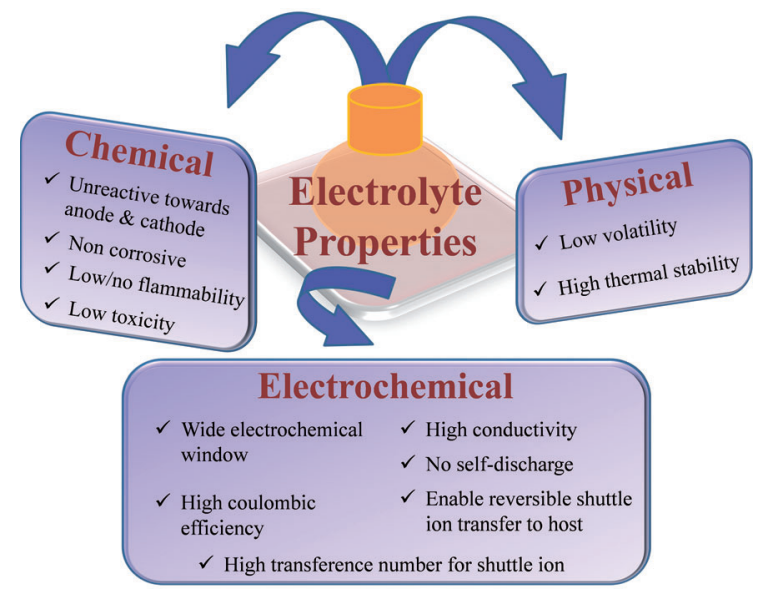

Figure 1. Properties desired for Mg battery electrolytes.

A key challenge of electrolyte development for rechargeable $\mathrm{Mg}$ batteries stems from the instability of simple ionic salts and polar aprotic solvents in the proximity of $\mathrm{Mg}$ metal. For example, conventional $\mathrm{Mg}$ salts such as $\left[\mathrm{ClO}_{4}\right]^{-},\left[\mathrm{BF}_{4}\right]^{-}$, and $[\mathrm{TFSI}]^{-}[\mathrm{TFSI}=$ bis(trifluoromethanesulfonyl)imide], and polar aprotic solvents such as nitriles and carbonates were found to 
decompose on the metal surface..$^{[5]}$ The resulting interfacial layer was found to be impermeable to $\mathrm{Mg}^{2+}$, preventing battery function. ${ }^{[6]}$ This unfortunate phenomenon has excluded a myriad of salt/solvent combinations from being considered as $\mathrm{Mg}$ battery electrolytes. ${ }^{[2,3 a, 5]}$

Over the past two decades, a number of systems with wide electrochemical windows and high conductivities have been developed. However, a common shortcoming of all of these electrolytes is their incompatibility with non-noble metals at operating voltages above around $2.5 \mathrm{~V}$ vs. $\mathrm{Mg}$, representing a key hurdle towards their practical use in Mg batteries. ${ }^{[2,7]}$ In this Concept, we will summarize recent advances aimed at tackling the existing challenges. We will focus on those developed by our group, involving a new design platform based on salts containing the $\mathrm{B}-\mathrm{H}$ motif that were shown to greatly alleviate the aforementioned issue.

\section{Established Electrolyte Design Strategies}

Over 80 years ago, it was discovered that ethereal solutions of Grignard reagents were capable of supporting the plating of highly pure $\mathrm{Mg}$ metal. ${ }^{[8]}$ However, the relatively low oxidation stability of most Grignard reagents (about $1.5 \mathrm{~V}$ vs. Mg;

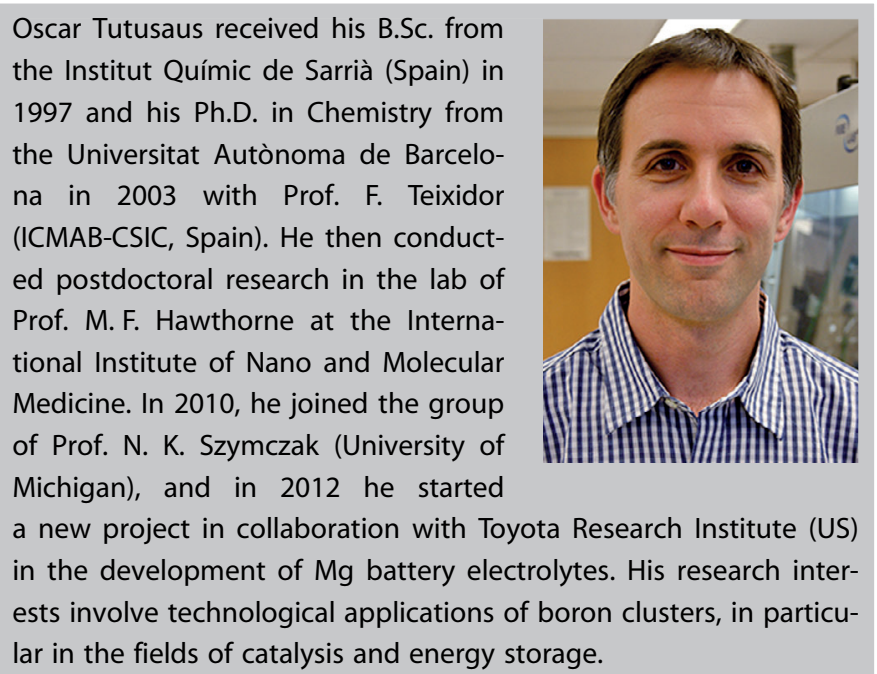

Rana Mohtadi obtained her B.Sc. in Chemical Engineering from the University of Jordan (1998, Jordan) and M.Sc. from the Technical University of Hamburg-Harburg (2001, Germany). In 2004, she received her Ph.D. from the University of South Carolina (US) with Prof. J.W. Van Zee, where she researched proton-exchange membrane fuel cells. In 2004, she joined Toyota Research Institute (US) and is currently a Principal Scientist. Her research inter-

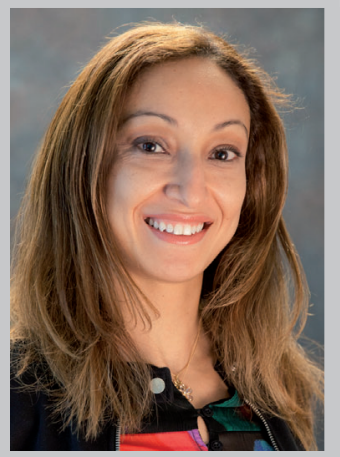
ests include fuel cells, hydrogen storage and novel battery chemistries. Notable achievements include receiving the R\&D100 award (2011) and the " 40 under 40 " recognition by the auto news (2014).

\begin{tabular}{|c|c|c|}
\hline Electrolyte & $\begin{array}{l}\text { Anodic stability } \\
\text { on Pt [V vs. Mg] }\end{array}$ & $\begin{array}{l}\text { Corrosivity threshold on } \\
316 \text { stainless steel[a] }[\mathrm{V} \text { vs. Mg] }\end{array}$ \\
\hline$n \mathrm{BuMgCl}$ & $\begin{array}{l}1.3^{[9]}-1.4^{[10 c]} \\
(2.0 \mathrm{M} \text { in THF) }\end{array}$ & $\mathrm{N} / \mathrm{A}$ \\
\hline $\mathrm{HMDSMgCl}^{[\mathrm{b}]}$ & $\begin{array}{l}2.1^{[11 \mathrm{a}]} \\
(1.0 \mathrm{M} \text { in THF) }\end{array}$ & $\mathrm{N} / \mathrm{A}$ \\
\hline $\mathrm{Mg}\left(\mathrm{BBu}_{2} \mathrm{Ph}_{2}\right)_{2}$ & $\begin{array}{l}2.0^{[5 \mathrm{a}, 10 \mathrm{c}]} \\
(0.25 \mathrm{M} \text { in THF) }\end{array}$ & $\mathrm{N} / \mathrm{A}$ \\
\hline (4-F-Ph)MgBr & $\begin{array}{l}2.4^{[18]} \\
(1 \mathrm{M} \text { in THF) }\end{array}$ & $\mathrm{N} / \mathrm{A}$ \\
\hline$(\mathrm{HMDS})_{2} \mathrm{Mg} / 2 \mathrm{AlCl}_{3}^{[\mathrm{b}]}$ & $\begin{array}{l}3.3^{[13 \mathrm{~b}]} \\
(0.25 \mathrm{M} \text { in THF) }\end{array}$ & $\mathrm{N} / \mathrm{A}$ \\
\hline & & $\begin{array}{l}2.6^{[13 \mathrm{~b}]} \\
(0.35 \mathrm{M} \text { in diglyme })\end{array}$ \\
\hline $\mathrm{Mg}\left(\mathrm{AlCl}_{2} \mathrm{BuEt}\right)_{2}$ & $\begin{array}{l}2.2^{[10 c]} \\
(0.25 \mathrm{M} \text { in THF })\end{array}$ & $\begin{array}{l}1.6^{[15 b]} \\
(0.25 \mathrm{M} \text { in THF) }\end{array}$ \\
\hline $\mathrm{PhMgCl} / \mathrm{AlCl}_{3}$ & $\begin{array}{l}3.3^{[13 \mathrm{~g}]} \\
(0.4 \mathrm{M} \text { in THF) }\end{array}$ & $\mathrm{N} / \mathrm{A}$ \\
\hline $\begin{array}{l}{\left[\mathrm{Mg}_{2} \mathrm{Cl}_{3}-(\mathrm{THF})_{6}\right]} \\
{\left[(\mathrm{HMDS}) \mathrm{AlCl}_{3}\right]^{[\mathrm{bb}}}\end{array}$ & $\begin{array}{l}3.3^{[13 c]} \\
(0.2 \mathrm{M} \text { in THF) }\end{array}$ & $\mathrm{N} / \mathrm{A}$ \\
\hline $\mathrm{MgCl}_{2} / 2 \mathrm{AlCl}_{3}$ & $\begin{array}{l}\left.3.1^{[13 \mathrm{~d}]}\right] \\
(0.25 \mathrm{M} \text { in DME) }\end{array}$ & $N / A$ \\
\hline $\mathrm{MgCl}_{2} / 2 \mathrm{AlEtCl}_{2}$ & $\begin{array}{l}2.9^{[13 \mathrm{e}]} \\
(0.67 \mathrm{M} \text { in THF) }\end{array}$ & $1.8^{[\mathrm{c}[13 \mathrm{e}]}$ \\
\hline $\mathrm{Mes}_{3} \mathrm{~B} /(\mathrm{PhMgCl})_{2}^{[\mathrm{d}]}$ & $\begin{array}{l}3.5^{[10 \mathrm{~b}]} \\
(0.5 \mathrm{M} \text { in THF) }\end{array}$ & $\begin{array}{l}2.2^{[10 \mathrm{~b}]} \\
(0.5 \mathrm{M} \text { in THF) }\end{array}$ \\
\hline$(\mathrm{FMPMC})_{2}-\mathrm{AlCl}_{3}{ }^{[\mathrm{e}]}$ & $\begin{array}{l}2.9^{[13 f]} \\
(0.5 \mathrm{M} \text { in THF) }\end{array}$ & N/A \\
\hline
\end{tabular}

[a] Taken as the anodic stability in 316 Stainless Steel. [b] HMDS = hexamethyldisilazide. [c] Method not described. [d] Mes =3,5-dimethylphenyl. [e] FMPMC = magnesium 4-(trifluoromethyl)phenolate chloride.

Table 1) and their reactivity towards many cathode materials precluded their use as electrolytes in battery systems. ${ }^{[9,5 a]}$ Capitalizing on their compatibility with $\mathrm{Mg}$ metal, initial research and development efforts relied on organomagnesium compounds as platforms to create electrolytes with increased anodic stability.

A seminal work published by Gregory et al. in 1990 introduced electrolytes based on magnesium bis(organoborate) salts and amidomagnesium halides as improvements to organomagnesium reagents. ${ }^{[5 a]}$ The reported methodologies, used to derive each compound type, became the basis of two strategies widely adopted to improve electrolyte performance (Figure 2). In the first approach, suitable Lewis acids based on group 13 elements (primarily $\mathrm{B}$ and $\mathrm{Al}$ ) are added to strong Lewis basic organic anions present in Grignard reagents, ultimately yielding stable complex anions. ${ }^{[10]}$ For example, organoborate anions were obtained by using this strategy, ${ }^{[5 a]}$ displaying oxidative stability of $1.9 \mathrm{~V}$ vs. $\mathrm{Mg}$ and supporting $\mathrm{Mg}$ insertion into a cathode host material. Later, Aurbach et al. used stronger aluminium Lewis acids and reported a family of magnesium organo(halo)aluminates, displaying anodic stabilities ranging from 2.2 to $3.2 \mathrm{~V}$ vs. Mg. ${ }^{[2,10 a, c]}$ The second approach employed to improve the electrolyte performance stemmed from realizing that anions based on atoms more electronegative than carbon would be oxidatively more robust. Accordingly, the carbanion group in a Grignard reagent was initially re- 


\section{Mg-incompatible}
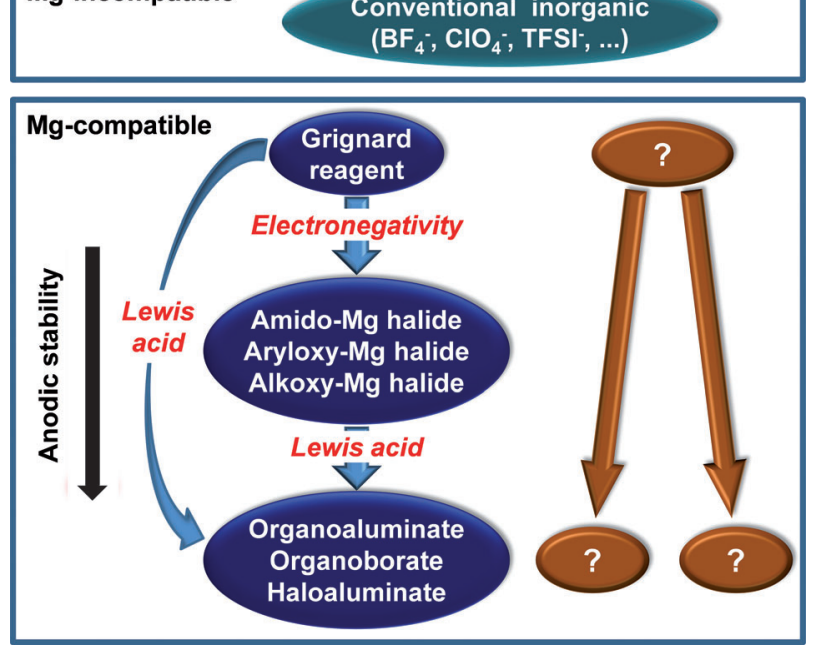

Figure 2. Design strategies for the development of electrolytes for rechargeable Mg battery. The ovals with question marks symbolize alternate design paths that do not rely on halo and organo reagents as a basis for further development.

placed by amides, ${ }^{[5 a, 11]}$ and later by alkoxides, ${ }^{[12]}$ aryloxides, or chlorides, often yielding compounds compatible with $\mathrm{Mg}$ metal. ${ }^{[13]}$ These could also be hybridized with the first approach (addition of a strong Lewis acid) to further increase their stability against electrochemical oxidation. ${ }^{[12,13]}$

At the beginning of this century, an important milestone was reported by Aurbach et al. who demonstrated the first, and only, example of a rechargeable Mg battery, enabled largely by the organo(halo)aluminate electrolytes they developed. The prototype provided $65 \mathrm{Wh} \mathrm{kg}^{-1}$ energy density by coupling a $\mathrm{Mg}$ metal anode with a Chevrel-phase $\mathrm{Mo}_{6} \mathrm{~S}_{8}$ cathode, and the voltage requirement $(2.0 \mathrm{~V}$ vs. $\mathrm{Mg})$ was fulfilled with the electrolyte $\mathrm{Mg}\left(\mathrm{AlCl}_{2} \mathrm{BuEt}\right)_{2}$ /tetrahydrofuran (THF). ${ }^{[10 \mathrm{c}]}$ As a further increase in the energy density is desired, creating higher voltage cathodes became of interest and, with that, so did electrolytes with improved electrochemical oxidative stability. Subsequent advancements following the two aforementioned strategies resulted in state-of-the-art electrolytes possessing enhanced electrochemical properties, which was evident from a highly reversible performance, high bulk conductivity, and widened electrochemical windows. ${ }^{[13]}$ Despite these scientific feats, these electrolytes were found to have several drawbacks that need to be overcome and are currently being addressed.

One of these relates to the use of volatile solvents, such as THF, where an optimal performance has been demonstrated in earlier reports. ${ }^{[10 a]}$ This solvent was used to study other electrolytes that were developed later; however, owing to its high volatility, less volatile/flammable ethers such as glymes are more desired for liquid electrolytes. ${ }^{[2,14]} \mathrm{A}$ recent advancement in this area was enabled by using non-Grignard-type haloaluminates based on amides such as (HMDS) ${ }_{2} \mathrm{Mg} / 2 \mathrm{AlCl}_{3}{ }^{[13 \mathrm{~b}]}$ and inorganic salts such as $\mathrm{MgCl}_{2} / 2 \mathrm{AlCl}_{3}{ }^{[13 \mathrm{~d}]}$ These electrolytes were shown to perform well in glymes, which offer a possible path to overcome this challenge.
Another important issue was related to the incompatibility with certain cathodes, such as sulfur. This is particularly prominent in systems containing nucleophilic anions or free Lewis acids. ${ }^{[2]}$ To tackle this issue, less nucleophilic organic amides such as those based on hexamethyldisilazide, ${ }^{[13 b, c]}$ or inorganic salts based on $\mathrm{MgCl}_{2}{ }^{[13 \mathrm{~d}, \mathrm{e}]}$ were proposed as potential solutions.

However, one standing and common limitation of this family of electrolytes is their recently discovered corrosive nature. ${ }^{[15]}$ Corrosion of non-noble metal electrodes is manifested by parasitic anodic current caused by metal dissolution. As a consequence, when anodic stability was tested on non-noble metal electrodes, a current was observed at potentials below that measured on noble metal and inert electrodes, representative of electrolyte decomposition.(Table 1). ${ }^{[16]}$ Therefore, it is critical that the oxidative stability of electrolytes is evaluated on a variety of non-noble metals. As the corrosion of current collectors has been linked to chloride ions, ${ }^{[17]}$ chloride-free electrolytes are deemed necessary. However, this not a trivial task, given that the design of state-of-the-art electrolytes that are compatible with Mg metal hinges on the two working principles previously described, typically involving either organomagnesium halide reagents or halogenated Lewis acids such as $\mathrm{AlCl}_{3}$. Although one obvious way to mitigate the corrosive behaviour would be to use chloride-free reagents, we chose to follow an approach granted to eliminate the problem at its core by discovering new $\mathrm{Mg}$ compatible systems that are halide free. Our quest was to create a new design platform that could be used as basis for electrolytes design, as depicted in Figure 2.

\section{Borohydrides: A Halide-Free Family of Electrolytes}

Going beyond the restraints imposed by halogen-based electrolytes required us to set forth in a new direction. It became necessary to explore a bottom-up approach based on new Mg-compatible systems. This would serve as an alternative platform towards the design of novel electrolytes. Given that Mg metal passivation in inorganic electrolytes was attributed to the insufficient reductive stability of the anion, ${ }^{[5 b]}$ we hypothesized that $\mathrm{Mg}$ salts of reducing anions should display compatibility with $\mathrm{Mg}$ metal. We were interested in reducing agents commonly used in chemical synthesis, which include complex metal hydrides, among which are borohydride salts. ${ }^{[19]}$ Our density functional calculations supported the possibility that $\left[\mathrm{BH}_{4}\right]^{-}$was of higher reductive stability than $\left[\mathrm{BF}_{4}\right]^{-}$, which is known to passivate Mg metal. ${ }^{[20]}$ To obtain a proof of concept, the salt was initially studied in THF, the solvent of choice for all other available $\mathrm{Mg}$ electrolytes reported at that time. Satisfyingly, cycling voltammetry experiments showed reversible $\mathrm{Mg}$ deposition/stripping with about $40 \%$ coulombic efficiency (Figure $3 \mathrm{a}$ ), whereas galvanostatic deposition confirmed the composition of the deposited material as $\mathrm{Mg}$ metal. ${ }^{[21]}$ This accomplishment constituted a breakthrough, as it represented the first inorganic salt that is compatible with Mg metal. 


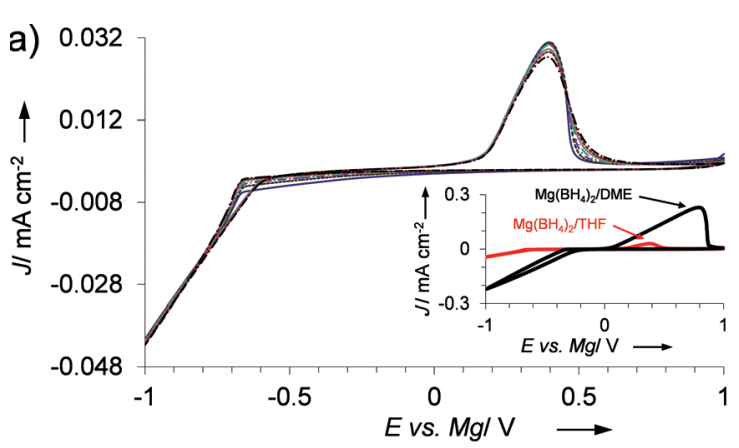

b)

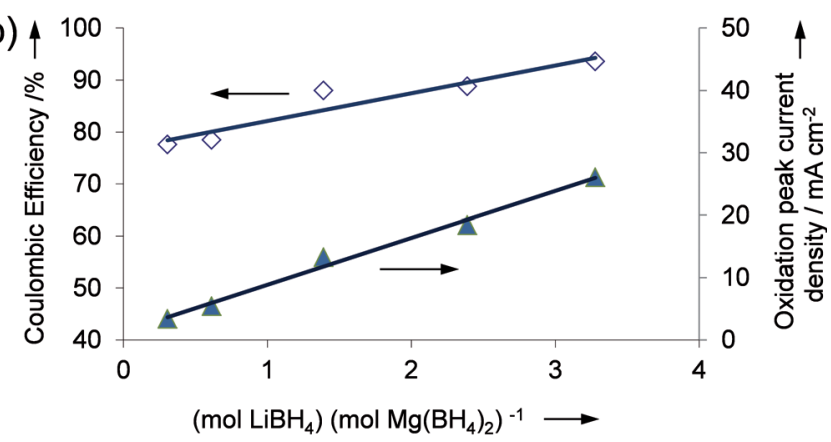

c)

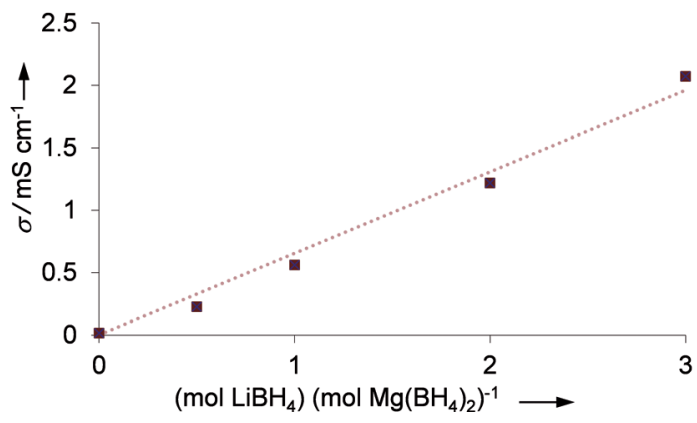

Figure 3. a) Cyclic voltammogram for $0.5 \mathrm{M} \mathrm{Mg}\left(\mathrm{BH}_{4}\right)_{2} / \mathrm{THF}$; inset compares the cyclic voltammograms in THF and in DME. Adopted from Ref. [21] with permission. Copyright 2012, Wiley-VCH Verlag GmbH \& Co. KGaA, Weinheim. Effect of $\mathrm{LiBH}_{4}$ addition to $0.18 \mathrm{M} \mathrm{Mg}\left(\mathrm{BH}_{4}\right)_{2} / \mathrm{DME}$ on b) the coulombic efficiency and $\mathrm{Mg}$ oxidation peak current density and c) conductivity.

Our first goal was to improve the electrochemical performance of $\mathrm{Mg}\left(\mathrm{BH}_{4}\right)_{2}$, focusing on increasing the coulombic efficiency and current density while lowering the deposition overpotential. In the state-of-the-art organomagnesium and related electrolytes, that is typically achieved by addition of aluminium- or boron-based Lewis acids; however, as the borohydride structure is not amenable to such methodologies, the development of alternate strategies is deemed necessary. We investigated the nature of species in the electrolyte to get information on the cation coordination sphere. Spectroscopic features of $\mathrm{Mg}\left(\mathrm{BH}_{4}\right)_{2} / \mathrm{THF}$ solutions resembled those of other covalent borohydrides, indicating the prevalence of strong contact ion pairs. ${ }^{[21]}$ Poor dissociation into ionic species was further corroborated by the measured low conductivity of $0.01 \mathrm{mS} \mathrm{cm}^{-1}$. Enhanced salt dissociation can be enabled by improving the coordinating ability of the solvent through increase of its dielectric constant and/or denticity. Polar aprotic solvents, such as dimethlysulfoxide (DMSO), are known to provide solvent-separated ion pairs consisting of a "naked" unco- ordinated anion and a solvated $\left[\mathrm{Mg}(\mathrm{DMSO})_{6}\right]^{2+}$ cation. ${ }^{[22]}$ We observed complete salt dissociation by using infrared spectroscopy of $\mathrm{Mg}\left(\mathrm{BH}_{4}\right)_{2}$ in DMSO (Figure $\mathrm{S} 1$ ), which is consistent with its solvate structure reported previously. ${ }^{[23]}$ Unfortunately, $\mathrm{Mg}\left(\mathrm{BH}_{4}\right)_{2} / \mathrm{DMSO}$ electrolyte solution was found to be unsuitable, as passivation of $\mathrm{Mg}$ metal occurred because of solvent decomposition. On the other hand, the chelating solvent 1,2dimethoxyethane (DME) successfully enhanced salt dissociation. ${ }^{[21]}$ As a result, despite the lower solubility of $\mathrm{Mg}\left(\mathrm{BH}_{4}\right)_{2}$ in $D M E$, a tenfold increase in current density, $50 \%$ increase in coulombic efficiency, and a $0.2 \mathrm{~V}$ decrease in deposition overpotentials were obtained (Figure 3.a, inset). In contrast, higher glymes, such as diglyme, had an adverse effect on the electrochemical performance, owing to reduced solubility of $\mathrm{Mg}\left(\mathrm{BH}_{4}\right)_{2}$ $(<0.05 \mathrm{M})$, establishing DME as the optimum solvent for this system.

Having identified the association between $\mathrm{Mg}^{2+}$ and $\left[\mathrm{BH}_{4}\right]^{-}$ as one of the critical factors affecting $\mathrm{Mg}\left(\mathrm{BH}_{4}\right)_{2}$ electrochemical performance, we sought additives that could modify ion speciation in DME. A borohydride salt containing a reductively stable anion, such as $\mathrm{LiBH}_{4}$, was studied as a mean to alter ion dissociation equilibria through the common-ion effect. ${ }^{[21]}$ Cyclic voltammetry experiments revealed extraordinary improvements, with up to $94 \%$ coulombic efficiency and 100 -fold increase in $\mathrm{Mg}$ stripping peak current density (Figure $3 \mathrm{~b}$ ). The ionic conductivity in $\mathrm{Mg}\left(\mathrm{BH}_{4}\right)_{2} / \mathrm{DME}$ was found to increase when $\mathrm{LiBH}_{4}$ was added (Figure $3 \mathrm{c}$ ), where up to $2 \mathrm{mS} \mathrm{cm}^{-1}$ was obtained. In fact, this ionic conductivity was on par with the best performing $\mathrm{Mg}$ electrolytes and tracked well with the enhancements observed with Mg deposition/stripping. In addition, this electrolyte system was found to support reversible $\mathrm{Mg}^{2+}$ insertion/extraction into a Chevrel-phase cathode. ${ }^{[21]}$ These enhancements, coupled with the absence of $\mathrm{Li}^{+}$deposition and insertion into $\mathrm{Mo}_{6} \mathrm{~S}_{8}$ cathode suggest the formation of complex species such as $\left[\mathrm{Li}\left(\mathrm{BH}_{4}\right)_{x}\right]^{\mathrm{y}-}$ ions, which are currently under investigation.

The presence of the $\mathrm{LiBH}_{4}$ additive also displayed other effects, such an increased solubility of $\mathrm{Mg}\left(\mathrm{BH}_{4}\right)_{2}$ in glymes with higher denticity, coupled with high coulombic efficiencies in these solvents. ${ }^{[2 \mathrm{~b}]}$ In a later study, Shao et al. also applied our strategy to further optimize the $\mathrm{Mg}\left(\mathrm{BH}_{4}\right)_{2} / \mathrm{LiBH}_{4}$ electrolyte composition. Notably, using diglyme as solvent and increasing $\mathrm{LiBH}_{4}$ content provided a coulombic efficiency for Mg deposition/stripping close to $100 \%{ }^{[24]}$ These studies further supported the non-trivial role of $\mathrm{LiBH}_{4}$ as an additive; for instance, different coulombic efficiencies were obtained from DME and diglyme electrolyte solutions, despite their similar ionic conductivity. Even more intriguing is the role of the cation. Whereas we observed enhancement by using other borohydrides such as $\mathrm{NaBH}_{4}$, it was not as pronounced as those found with $\mathrm{LiBH}_{4}$ for analogues compositions. For example, 3:1 $\mathrm{NaBH}_{4} / \mathrm{Mg}\left(\mathrm{BH}_{4}\right)_{2}$ in DME displayed a lower coulombic efficiency and current density by 5 and $60 \%$, respectively (Figure S2). Further optimizations and understanding of the borohydride electrolytes are currently under investigation in our labs.

Following the demonstration of a highly reversible electrolyte, we examined the electrolyte stability against the electro- 
chemical oxidation on different materials. Surprisingly, the stability on platinum (1.7 V vs. Mg) was lower than those on stainless steel and glassy carbon ( 2.2 and $2.3 \mathrm{~V}$ vs. Mg, respectively), which is likely caused by the catalytic effects of Pt metal on $\left[\mathrm{BH}_{4}\right]^{-}$decomposition through strong dissociative adsorption; this indicates the importance of $\left[\mathrm{BH}_{4}\right]^{-}$-electrode surface interactions. ${ }^{[25]}$ Notably, as the borohydride electrolytes are not corrosive, the stability on steel is similar to that observed for other electrolytes that are twice as stable on Pt. Most importantly, borohydride electrolytes remain the only relatively ionic and halide free salts that are highly compatible with $\mathrm{Mg}$ metal.

\section{Aromatic Borohydrides: The Next Step to Stability}

Although some of the electrochemical properties of $\mathrm{Mg}\left(\mathrm{BH}_{4}\right)_{2}$ electrolyte solutions can be adjusted by the judicious choice of solvent and additives, improving its oxidative stability requires more profound modifications. $\mathrm{Mg}\left(\mathrm{BH}_{4}\right)_{2}$ has been extensively studied as a potential candidate for hydrogen storage, because of its high theoretical $\mathrm{H}_{2}$ content. ${ }^{[26]}$ Several studies have reported the undesired formation of higher boranes during thermal decomposition of $\mathrm{Mg}\left(\mathrm{BH}_{4}\right)_{2}$, which are detrimental for reversible $\mathrm{H}_{2}$ storage. ${ }^{[27]}$ Among them, magnesium dodecahydrododecaborate $\left(\mathrm{MgB}_{12} \mathrm{H}_{12}\right)$ has been identified as the major byproduct. ${ }^{[27 b]}$ The $\left[\mathrm{B}_{12} \mathrm{H}_{12}\right]^{2-}$ dianion is the most stable representative of the closo-borane family, a group of higher borane clusters with stoichiometry $\left[\mathrm{B}_{n} \mathrm{H}_{n}\right]^{2-}(n=6-12)$ and closed deltahedral structures (polyhedral with triangular faces). ${ }^{[28]}$ Such compounds display an unusual stability relative to neutral binary boron hydrides with open structures originally discovered by Stock. ${ }^{[29]}$ The source of their stability arises from the tangentially delocalized sigma bonding present in the boron framework and are, therefore, regarded as three-dimensional aromatic species. ${ }^{[30]}$ Indeed, the two negative charges in $\left[\mathrm{B}_{12} \mathrm{H}_{12}\right]^{2-}$ are required to fulfil aromatic electron count and are, thus, delocalized over the cluster. As a consequence, the oxidation potential for the $\left[\mathrm{B}_{12} \mathrm{H}_{12}\right]^{2-}$ dianion has been reported to occur above $4 \mathrm{~V}$ (vs. Mg), whereas no accounts of its electrochemical reduction have been found. ${ }^{[31]}$ In a broad sense, $\left[\mathrm{B}_{12} \mathrm{H}_{12}\right]^{2-}$ can be regarded as the aromatic analogue of $\left[\mathrm{BH}_{4}\right]^{-}$, the same as benzene is to methane.

In a first approach towards exploring boron clusters as $\mathrm{Mg}$ electrolytes, $\mathrm{MgB}_{12} \mathrm{H}_{12}$ was targeted. ${ }^{[20]}$ Even though the compound was successfully synthesized, its insolubility in ethers hampered electrochemical studies. It is likely that the high charge associated with both the anion and the cation is the main reason behind the low solubility. Isostructural and isoelectronic families of closo-carboranes exist, in which one or more $[\mathrm{BH}]^{-}$units are formally replaced by isoelectronic $[\mathrm{CH}]$ units, providing a route to reduce the total cluster charge. Among them, neutral $m$-carborane $\left(1,7-\mathrm{C}_{2} \mathrm{~B}_{10} \mathrm{H}_{12}\right)$ has previously been reported to possess comparable electrochemical stability to that of $\left[\mathrm{B}_{12} \mathrm{H}_{12}\right]^{2-}$ anion and was chosen as the entry point to soluble $\mathrm{Mg}$ salts containing boron clusters. ${ }^{[32]}$ For a proof of concept, we selected $m$-carboranyl magnesium chloride to enable high solubility $(>1 \mathrm{M})$, aided by the $\mathrm{Mg}-\mathrm{C}$ covalent bond character. ${ }^{[20]}$ A relatively high bulk conductivity of $0.6 \mathrm{mS} \mathrm{cm}^{-1}$ (at $0.1 \mathrm{~g} \mathrm{~mL}^{-1}$ ) was measured, indicative of salt dissociation. In addition, in contrast with other electrolytes based on the $\left[\mathrm{Mg}_{2} \mathrm{Cl}_{3}\right]^{+}$cation, recrystallized $m$-carboranyl magnesium chloride salt (1) displayed a complex anion containing a $\mathrm{Mg}$ atom (Figure $4 \mathrm{a}$ ). Solutions of $\mathrm{Mg}\left(1,7-\mathrm{C}_{2} \mathrm{~B}_{10} \mathrm{H}_{11}\right) \mathrm{Cl}$ exhibit-
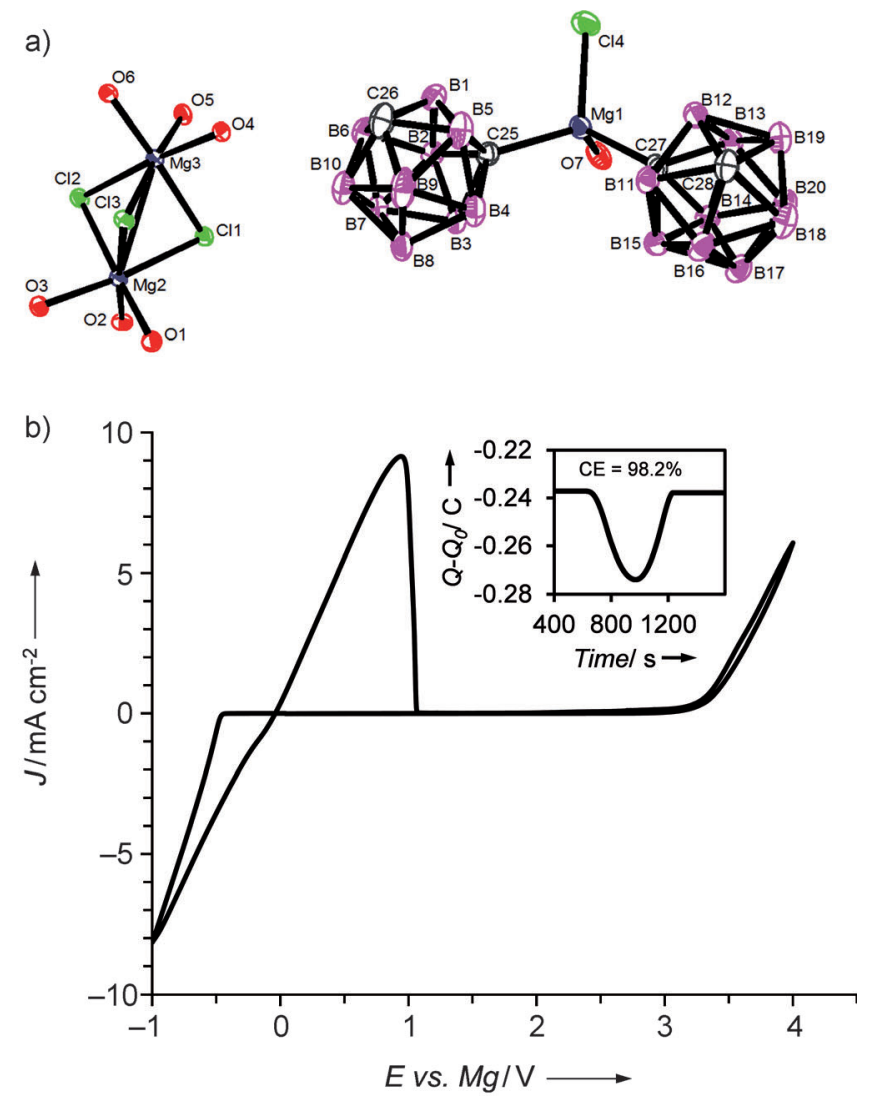

Figure 4. a) X-Ray structure of 1. Thermal ellipsoids are shown at $50 \%$ probability. Hydrogen atoms and THF carbon atoms are omitted for clarity (i.e. each oxygen atom represents a THF solvent molecule). b) Cyclic voltammogram of a solution of $\mathrm{Mg}\left(1,7-\mathrm{C}_{2} \mathrm{~B}_{10} \mathrm{H}_{11}\right) \mathrm{Cl}\left(0.1 \mathrm{~g} \mathrm{~mL}^{-1}\right.$ in THF); inset: charge balance of $\mathrm{Mg}$ deposition/stripping. Adopted from Ref. [20] with permission. Copyright 2014, Wiley-VCH Verlag GmbH \& Co. KGaA, Weinheim.

ed a reversible redox couple (coulombic efficiency $>98 \%$ ) with an onset potential and peak shape consistent with Mg deposition and stripping (Figure $4 \mathrm{~b}$ ). Note that 1 was confirmed to be one of the electroactive species, as a similar reversible performance as the bulk was found. ${ }^{[20]}$ Additionally, a high anodic stability of $3.2 \mathrm{~V}$ (vs. Mg) was observed, remarkably higher than the $2.4 \mathrm{~V}$ displayed by $4-\mathrm{F}-\mathrm{PhMgBr} / \mathrm{THF}^{[18]}$ which was considered the best Grignard compound until that date. It is also comparable with electrolytes generated by addition of Lewis acids such as $\mathrm{AlCl}_{3}$ or $\mathrm{BR}_{3}$ to Grignard reagents, amidomagnesium compounds, or $\mathrm{MgCl}_{2}$. ${ }^{[33]}$

Most importantly, the oxidation onset potential determined by linear-sweep voltammetry experiments on a variety of working electrodes was similar (3.2 V vs. $\mathrm{Mg}$ ) for $\mathrm{Pt}, 316-\mathrm{SS}$, and $\mathrm{Al}$ (Figure S3). ${ }^{[20]}$ In previous studies with other halide-containing electrolyte solutions, the oxidation onset was always 
highly dependent on the electrode material. ${ }^{[33]}$ Chronoamperometry experiments further supported the measured oxidative stability (Figure S3). Interestingly, this result constitutes the highest reported stability on a steel electrode to date, suggesting that the closo-borane scaffold does indeed offer unique stability when incorporated into a Mg-battery electrolyte material. This electrolyte also supported $\mathrm{Mg}$-ion insertion into a host cathode material such as Chevrel-phase $\mathrm{Mo}_{6} \mathrm{~S}_{8}$, which allowed for the demonstration of a battery. The battery was cycled and a stable reversible specific capacity was achieved (ca. $90 \mathrm{mAhg}^{-1}$ at $0.05 \mathrm{C}$; Figure S4). ${ }^{[20]}$

Despite attaining increased compatibility toward non-noble metals by using a closo-borane electrolyte, further improvements are still needed. That is, although the corrosivity has been lowered, it has not been eliminated; furthermore, as discussed before, excellent electrochemical performance needs to be achieved in a solvent other than THF. However, the results provided a proof of concept that boron clusters offer an opportunity for effectively tackling the existing challenges with current electrolytes. Further steps should be aimed at designing chloride-free boron cluster electrolytes capable of supporting excellent $\mathrm{Mg}$ plating/deposition performance in THF free solvents and are compatible with non-noble metals.

\section{Conclusions and Outlook}

Rechargeable batteries are one of the most effective means of storing energy, and rechargeable $\mathrm{Mg}$ batteries hold promise for increasing the battery energy density (i.e. versus Li-ion batteries). However, this technology is currently in its infancy and facing substantial hurdles caused by the absence of practical electrolytes and cathodes. In particular, the development of electrolyte systems with wide electrochemical windows and high compatibility with battery components is crucial to discovering high-voltage cathodes.

Upon examining the progress made in the developments of Mg battery electrolytes over the past two decades, we felt that the design toolbox has been used exhaustively and may have limitations towards achieving the necessary goals. In this article, we explained a new bottom-up approach, which utilized borohydride salts. These were used as a new platform to design novel electrolytes, holding high promise to overcome existing challenges with prevalent halomagnesium-based compounds. High conductivities (ca. $2 \mathrm{mS} \mathrm{cm}^{-1}$ ), low overpotentials (ca. $-0.3 \mathrm{~V}$ vs. $\mathrm{Mg}$ ), and high current densities (i.e. Mg stripping peak current density $>20 \mathrm{~mA} \mathrm{~cm}^{-2}$ ) demonstrated the high potential of the borohydride family. Achieving these properties was possible through new ground rules set forth by a fundamental understanding of these systems, which enabled critical discoveries. The highly reversible and facile $\mathrm{Mg}$ deposition/ stripping kinetics underscored the uniqueness of the $\mathrm{BH}_{4}^{-}$ anion. To increase the oxidative stability of the borohydrides while preserving their attractive $\mathrm{B}-\mathrm{H}$ feature, we employed a new design strategy using three-dimensional and robust boron clusters. A model compound based on carboranyl magnesium chloride demonstrated compatibility with $\mathrm{Mg}$ metal while exhibiting a high anodic stability (3.2 V vs. $\mathrm{Mg}$ ) and the lowest corrosivity towards non-noble metals to date. Nonetheless, this is just the beginning of the journey, and making the boron cluster electrolytes soluble in the absence of chloride and demonstrating high performance in a non-THF solvent is the next big challenge. Certainly, anions based on the $\mathrm{B}-\mathrm{H}$ motif offer a new landscape in the universe of rechargeable $\mathrm{Mg}$ battery electrolytes and pave the way for designing practical rechargeable $\mathrm{Mg}$ batteries.

\section{Experimental Section}

Experimental details are shown in the Supporting Information.

\section{Acknowledgements}

R.M. and O.T. would like to thank Dr. T.S. Arthur and Dr. Koji Suto for their insightful suggestions. Special thanks for Prof. Nathaniel Szymczak for his insightful suggestions. Funding for O.T. was provided from the Chemistry Department at the University of Michigan. Funding for meeting the cost of this article was provided by Toyota Motor Engineering and Manufacturing North America TEMA.

Keywords: batteries - boron - electrolyte - energy storage magnesium

[1] J. Dahn, G. M. Ehrlich in Handbook of Batteries, $4^{\text {th }}$ ed., (Eds.: D. Linden, T. B. Reddy), McGraw-Hill, New York, 2011, pp. 26.2.

[2] H. D. Yoo, I. Shterenberg, Y. Gofer, G. Gershinsky, N. Pour, D. Aurbach, Energy Environ. Sci. 2013, 6, 2265-2279.

[3] a) D. Aurbach, I. Weissman, Y. Gofer, E. Levi, Chem. Rec. 2003, 3, 61-73; b) M. Matsui, J. Power Sources 2011, 196, 7048-7055.

[4] K. Xu, Chem. Rev. 2004, 104, 4303-4417.

[5] a) T. D. Gregory, R. J. Hoffman, R. C. Winterton, J. Electrochem. Soc. 1990, $137,775-780$; b) Z. Lu, A. Schechter, M. Moshkovich, D. Aurbach, J. Electroanal. Chem. 1999, 466, 203-217.

[6] Note, however, that two recent publications have indicated some possibility to deposit/strip Mg metal from $\mathrm{Mg}(\mathrm{TFSI})_{2}$ solutions in ethereal solvents. However, in both cases, a relatively low initial coulombic efficiency or significant worsening in depositing/stripping performance was observed over cycling. More details in: a) S.-Y. Ha, Y.-W. Lee, S. W. Woo, B. Koo, J.-S. Kim, J. Cho, K. T. Lee, N.-S. Choi, ACS Appl. Mater. Interfaces 2014, 6, 4063-4073; b) Y. Orikasa, T. Masese, Y. Koyama, T. Mori, M. Hattori, K. Yamamoto, T. Okado, Z.-D. Huang, T. Minato, C. Tassel, J. Kim, Y. Kobayashi, T. Abe, H. Kageyama, Y. Uchimoto, Sci. Rep. 2014, 4, 5622.

[7] J. Muldoon, C. B. Bucur, A. G. Oliver, T. Sugimoto, M. Matsui, H. S. Kim, G. D. Allred, J. Zajicek, Y. Kotani, Energy Environ. Sci. 2012, 5, $5941-$ 5950; R. Mohtadi, F. Mizuno, Beilstein J. Nanotechnol. 2014, 5, 1291 1311.

[8] D. M. Overcash, F. C. Mathers, Trans. Electrochem. Soc. 1933, 64, 305311.

[9] W. V. Evans, F. H. Lee, C. H. Lee, J. Am. Chem. Soc. 1935, 57, 489-490.

[10] a) D. Aurbach, H. Gizbar, A. Schechter, O. Chusid, H. E. Gottlieb, Y. Gofer, I. Goldberg, J. Electrochem. Soc. 2002, 149, A115-A121; b) Y.-s. Guo, F. Zhang, J. Yang, F.-f. Wang, Y. NuLi, S.-i. Hirano, Energy Environ. Sci. 2012, 5, 9100-9106; c) D. Aurbach, Z. Lu, A. Schechter, Y. Gofer, H. Gizbar, R. Turgeman, Y. Cohen, M. Moshkovich, E. Levi, Nature 2000, 407, 724727.

[11] a) C. Liebenow, Z. Yang, P. Lobitz, Electrochem. Commun. 2000, 2, $641-$ $645 ; b)$

Q. S. Zhao, Y. N. NuLi, Y. S. Guo, J. Yang, J. L. Wang, Electrochim. Acta 2011, 56, 6530-6535. 
[12] C. Liao, B. Guo, D.-e. Jiang, R. Custelcean, S. M. Mahurin, X.-G. Sun, S. Dai, J. Mater. Chem. A 2014, 2, $581-584$.

[13] a) F.-f. Wang, Y.-s. Guo, J. Yang, Y. Nuli, S.-i. Hirano, Chem. Commun. 2012, 48, 10763-10765; b) Z. Zhao-Karger, X. Zhao, O. Fuhr, M. Fichtner, RSC Adv. 2013, 3, 16330-16335; c) H. S. Kim, T. S. Arthur, G. D. Allred, J. Zajicek, J. G. Newman, A. E. Rodnyansky, A. G. Oliver, W. C. Boggess, J. Muldoon, Nat. Commun. 2011, 2, 427; d) R. E. Doe, R. Han, J. Hwang, A. J. Gmitter, I. Shterenberg, H.D. Yoo, N. Pour, D. Aurbach, Chem. Commun. 2014, 50, 243-245; e) T. Liu, Y. Shao, G. Li, M. Gu, J. Hu, S. Xu Z. Nie, X. Chen, C. Wang, J. Liu, J. Mater. Chem. A 2014, 2, 3430-3438; f) E. G. Nelson, J. W. Kampf, B. M. Bartlett, Chem. Commun. 2014, 50 5193-5195; g) O. Mizrahi, N. Amir, E. Pollak, O. Chusid, V. Marks, H. Gottlieb, L. Larush, E. Zinigrad, D. Aurbach, J. Electrochem. Soc. 2008, 155 A103-A109.

[14] Y. Gofer, N. Pour, D. Aurbach in Electrolytic Solutions for Rechargeable Magnesium Batteries. Lithium Batteries: Advanced Technologies and Applications, (Eds. B. Scrosati, K. M. Abraham, W. Van Schalkwijk, J. Hassoun), Wiley:-VCH:Weinheim, Germany 2013; pp. 328-345.

[15] a) US Patent 2011159381; b) D. Lv, T. Xu, P. Saha, M. K. Datta, M. L. Gordin, A. Manivannan, P. N. Kumta, D. Wang, J. Electrochem. Soc. 2013 160, A351-A355.

[16] a) K. Xu., Chem. Rev. 2004, 104, 4303-4417; b) G. T. Burstein, C. Liu, R. M. Souto, S. P. Vines, Corros. Eng. Sci. Technol. 2004, 39, 25-30.

[17] J. Muldoon, C. B. Bucur, A. G. Oliver, J. Zajicek, G. D. Allred, W. C. Bog gess, Energy Environ. Sci. 2013, 6, 482-487.

[18] Y. Guo, J. Yang, Y. NuLi, J. Wang, Electrochem. Commun. 2010, 12, 1671 1673.

[19] a) H.C. Brown, S. Krishnamurthy, Tetrahedron 1979, 35, 567-607; b) E. R. H. Walker, Chem. Soc. Rev. 1976, 5, 23-50.

[20] T. J. Carter, R. Mohtadi, T. S. Arthur, F. Mizuno, R. Zhang, S. Shirai, J. W. Kampf, Angew. Chem. Int. Ed. 2014, 53, 3173-3177; Angew. Chem. 2014 126, 3237-3241.
[21] a) R. Mohtadi, M. Matsui, T. S. Arthur, S.-J. Hwang, Angew. Chem. Int. Ed. 2012, 51, 9780-9783; Angew. Chem. 2012, 124, 9918-9921; b) US Patent 20140038037.

[22] A. Jaenschke, J. Paap, U. Behrens, Organometallics 2003, 22, 1167-1169.

[23] M. Bremer, H. Nöth, M. Warchhold, Eur. J. Inorg. Chem. 2003, 2003, 111 119.

[24] Y. Y. Shao, T. B. Liu, G. S. Li, M. Gu, Z. M. Nie, M. H. Engelhard, J. Xiao, D. P. Lv, C. M. Wang, J. G. Zhang, J. Liu, Sci. Rep. 2013, 3, 3130-3137.

[25] M. C. S. Escaño, E. Gyenge, R. L. Arevalo, H. Kasai, J. Phys. Chem. C 2011, 115, $19883-19889$.

[26] a) H.-W. Li, Y. Yan, S. Orimo, A. Zettel, C. M. Jensen, Energies 2011, 4, 185-214; b) K. Chłopek, C. Frommen, A. Leon, O. Zabara, M. Fichtner, J. Mater. Chem. 2007, 17, 3496-3503.

[27] a) H. W. Li, K. Miwa, N. Ohba, T. Fujita, T. Sato, Y. Yan, S. Towata, M. W. Chen, S. Orimo, Nanotechnology 2009, 20, 204013; b) G. L. Soloveichik, Y. Gao, J. Rijssenbeek, M. Andrus, S. Kniajanski, R. C. Bowman, S.-J. Hwang, J.-C. Zhao, Int. J. Hydrogen Energy 2009, 34, 916-928.

[28] R. B. King, Chem. Rev. 2001, 101, 1119-1152.

[29] A. Stock, Hydrides of Boron and Silicon, Cornell University Press, Ithaca, NY, 1933.

[30] Z. Chen, R. B. King, Chem. Rev. 2005, 105, 3613-3642.

[31] a) J. H. Morris, H. J. Gysling, D. Reed, Chem. Rev. 1985, 85, 51-76; b) R. T. Boeré, S. Kacprzak, M. Kessler, C. Knapp, R. Reibau, S. Riedel, T. L. Roemmele, M. Ruhle, H. Scherer, S. Weber, Angew. Chem. Int. Ed. 2011, 50 549-552; Angew. Chem. 2011, 123, 572-575.

[32] L. I. Zakharkin, V. N. Kalinin, A. P. Snyakin, B. Acad. Sci. USSR CH+ 1968, 17, 194-196.

[33] See table 1.

Received: June 27, 2014

Revised: August 22, 2014

Published online on October 1, 2014 